\title{
Adhesive Properties of Proteolipid Protein Are Responsible for the Compaction of CNS Myelin Sheaths
}

\author{
Detlev Boison, ${ }^{1, a}$ Heinrich Büssow, ${ }^{2}$ Donatella D'Urso, ${ }^{3}$ Hans-Werner Müller, ${ }^{3}$ and Wilhelm Stoffel ${ }^{1}$ \\ 'Institut für Biochemie, Medizinische Fakultät, Universität Köln, D-50931 Köln, Germany, ${ }^{2}$ Anatomisches Institut, \\ Universität Bonn, D-53115 Bonn, Germany, and ${ }^{3}$ Neurologische Klinik, Medizinische Einrichtungen, D-40225 \\ Düsseldorf, Germany
}

\begin{abstract}
We have studied the molecular function of proteolipid protein (PLP), the main integral membrane protein of CNS myelin, by generating mice lacking PLP expression. Here, we demonstrate that these PLP-minus mice show no pleiotropism as mice carrying point mutations within the PLP gene. The expression of other myelin genes (myelin basic protein, MBP; myelin associated glycoprotein, MAG; UDPgalactose-ceramide galactosyl transferase, CGT) is unimpaired on the RNA level. Protein level immunofluorescence analysis by confocal microscopy reveals that in PLP-minus mice there is a complete absence of PLP, a scattered appearance of MBP, and MAG expressed more widely in regions lacking MBP staining, which may be a compensatory mechanism. In electron microscopy the myelin lamellae of the ensheathed CNS axons are loosely wrapped with wide extracellular spaces between turning loops. Intraperlod dense lines are missing. The lateral loops of the paranode form regular axoglial junctions. In PLP-minus mice axons with large diameters are loosely myelinated, whereas small axons remain unmyelinated. Functionally, the mutant mice show deficits in their locomotor activity. We propose that adhesion properties of the extracellular domains of PLP are responsible for the tight apposition of the plasma membrane processes of oligodendrocytes wrapping axons to form the compact myelin sheath.
\end{abstract}

[Key words: CNS myelin sheath, myelin compaction, proteolipid protein (PLP), transgenic mice, gene targeting, confocal microscopy]

During CNS maturation, oligodendrocyte processes address a multitude of axons forming a multilayered highly compacted membrane system between the nodes of Ranvier providing the insulator function of myelin. The ultrastructure of myelin is characterized by its periodicities between the major dense line (MDL), representing the cytosolic cleft between the apposed inner surfaces of the plasma membrane, and the intermediate dense line (IDL) imaging the space between the apposed exter-

\footnotetext{
Keceived Jan. 9, 1995; revised April 5, 1995; accepted April 11, 1995.

The support by the Deutsche Forschungsgemeinschaft, SFB 243 "Molekulare Analyse der Entwicklung zellulärer Systeme," (Sto A4), the Fritz-Thyssen and the Hertie-Stiftung is gratefully acknowledged. D.D. was supported as an A. von Humboldt fellow.

Correspondence should be addressed to Prof. W. Stoffel, Institut fuir Biochemie, Medizinische Fakultät, Universität Köln, Joseph-Stelzmann-Strasse 52, D-50931 Köln, Germany.

"Present address: Institute für Pharmakologie, Universität Zürich, Winterthurer Strasse 190, CH-8057 Zürich, Switzerland.

Copyright (C) 1995 Society for Neuroscience $0270-6474 / 95 / 155502-12 \$ 05.00 / 0$
}

nal membrane surface. This highly ordered structure has a specific composition of myelin proteins and complex lipids. Among the main myelin protein constituents are the myelin basic proteins, the MBPs (Eylar, 1970; Takahashi et al., 1985; Kamholz et al., 1986), and the hydrophobic proteolipid proteins PLP (30 $\mathrm{kDa}$ ) and DM20 (26 kDa) (Stoffel and Hillen, 1983; Milner et al., 1985; Schaich et al., 1986). Other proteins such as myelinassociated glycoprotein (MAG) (Arquini et al., 1987) are less abundant but have specific functions for myelin assembly.

The PLP gene, containing seven exons distributed over 17.5 kilobase (kb) (Diehl et al., 1986), is localized on chromosome Xq23 (Willard and Riordan, 1985). Numerous X-linked recessive mutants of PLP develop dysmyelinating diseases, for example, the jimpy mouse (Nave et al., 1986), or myelin-deficient rat (Boison and Stoffel, 1989). These mutations are associated with a pleiotropic phenotype due to premature death of CNS oligodendrocytes. Ultrastructurally, axons appear only scarcely myelinated. This myelin has formed an abnormal intraperiod dense line (Duncan et al., 1987, 1989). As a consequence, the severe hypomyelination inevitably leads to an early death of the individual. So far, the phenotype of only one PLP point mutation, the rumpshaker mouse (Schneider et al., 1992), with a nearly normal life span, exhibits different characteristics: a reduction in mutant PLP protein coupled with a marked hypomyelination, but no apparent loss of oligodendrocytes. These natural mutants represent phenotypes, caused by mutant forms of PLP and by secondary effects caused by the pleiotropism involved. They provide only limited information about the function of normal PLP/DM20.

We have chosen an in vivo approach to assess the basic functions of PLP/DM20 in transgenic mice. The PLP gene was targeted by two replacement vectors carrying different exon III variants (wild-type exon III as a control, wtneo; and a dm20 variant of exon III with a deletion of the PLP-specific 105bp, dm20neo) both containing a neogene in reverse orientation within intron III. We have shown that the insertion of the neomycine gene is dominant over exon III mutations and leads to a knock out of PLP expression. The targeting vectors and the generation of PLP-minus mice have been described recently (Boison and Stoffel, 1994).

In the present study, we have investigated the impact of the loss of PLP structure and function biochemically, immunohistochemically, and morphologically. We conclude from our experiments that adhesive domains of PLP are responsible for the compact structure of the myelin sheaths of CNS axons. Furthermore, we discuss the phenotypic differences between the 


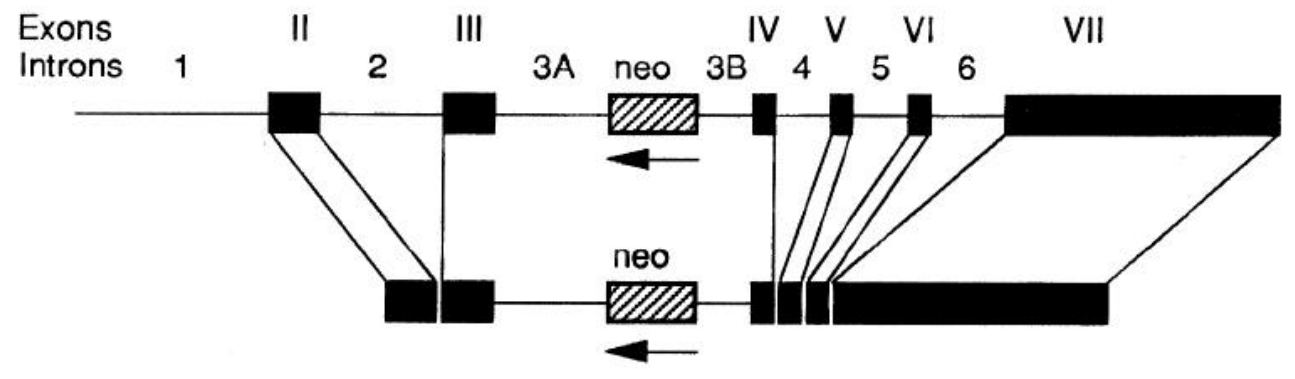

Figure 1. Structure of the $5.2 \mathrm{~kb}$ splicing product of the mutated PLP gene. Top, hnRNA; bottom, mRNA. Exons are numbered in Roman, introns in Arabic numerals, and are represented by black boxes and thin lines, respectively. The neo-cassette from $\mathrm{p}$ MCIneopolyA (Stratagene, La Jolla, CA) inserted in reverse transcriptional orientation (arrow) is indicated as a hatched box.

PLP-minus mouse and the well-known point mutations of the PLP gene.

\section{Materials and Methods}

Animals. PLP-minus mice (Boison and Stoffel, 1994) from our transgenic breeding colony were sacrificed at ages between 18 and $44 \mathrm{~d}$ for RNA and myelin preparations and perfused with glutaraldehyde (6\% in

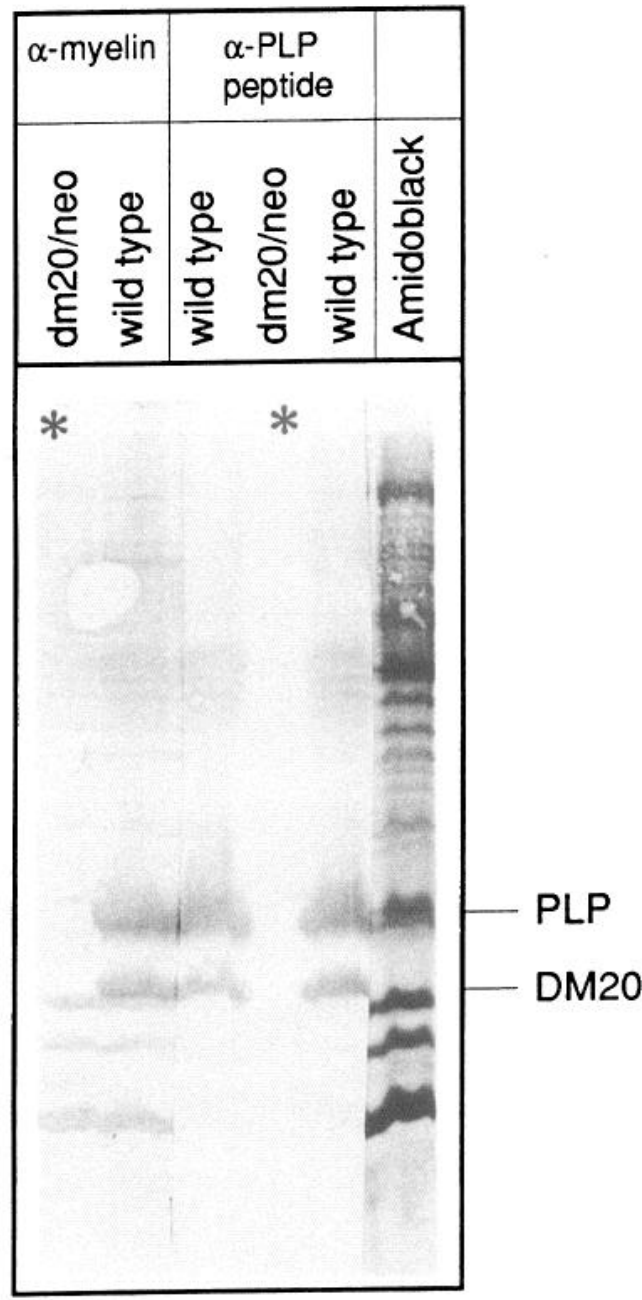

Figure 2. Western blot of myelin preparations of wild-type and transgenic PLP-minus mice. After size fractionation by SDS-PAGE, proteins were transferred to nitrocellulose by semidry blotting and immunostaining using 1:400 dilutions of anti-PLP peptide antibodies and anti-myelin polyclonal rabbit serum as a control. The predominant bands in wildtype samples are at a position identical to that of PLP and DM20. No signal is visible in samples from homozygous dm20neo mutant mice. The anti-myelin serum indicates the myelin basic proteins (MBPs) in both mutant and wild-type mice, but PLP and DM20 is lacking in the mutant lane.
PBS) for electron microscopy of optic nerve and spinal cord. Agematched wild-type C57/BL6 and CD-1 mice and heterozygous mutant animals were used as controls.

RNA analysis. Total RNA of the brain was isolated as described (Chomczynski and Sacchi, 1987). RNA (15 $\mu \mathrm{g}$ ) was separated on $1.5 \%$ agarose formaldehyde gels and blotted onto nitrocellulose (BA 85 , Schleicher and Schüll $\mathrm{GmbH}$, Dassel, Germany) with $20 \times$ SSC. After baking for $2 \mathrm{hr}$ at $80^{\circ} \mathrm{C}$, the membrane was prehybridized in $50 \%$ formamide, $50 \mathrm{~mm}$ phosphate buffer, $\mathrm{pH} 6.8,5 \times \mathrm{SSC}, 1 \times$ Denhardt's, and $100 \mu \mathrm{g} / \mathrm{ml}$ salmon sperm DNA for $4 \mathrm{hr}$ at $42^{\circ} \mathrm{C}$. Subsequently, the membrane was hybridized in fresh buffer containing $10 \%$ dextran sulfate and $2 \times 10^{5} \mathrm{cpm} / \mathrm{ml}{ }^{32} \mathrm{P}$-labeled probe over night at $42^{\circ} \mathrm{C}$. The membrane was washed $4 \times$ for $5 \mathrm{~min}$ in $2 \times$ SSC, $0.1 \%$ SDS at room temperature, and twice for $15 \mathrm{~min}$ in $0.1 \times \mathrm{SSC}, 0.1 \%$ SDS at $50^{\circ} \mathrm{C}$.

Hybridization probes. The following cDNA fragments were ${ }^{32} \mathrm{P}-\mathrm{la}-$ beled with the random priming DNA labeling kit (Boehringer, Mannheim, Germany) according to the manufacturer's recommendations and used as hybridization probes for the oligodendrocyte-specific mRNAs: PLP, a genomic $700 \mathrm{bp} \mathrm{Bgl} \mathrm{II} \mathrm{fragment} \mathrm{containing} \mathrm{sequences} \mathrm{of} \mathrm{exon}$ III and intron IIIA; MBP, a 620 bp PstI fragment of rat MBP (complete coding region); CGT, $700 \mathrm{bp} \mathrm{3'-terminal} \mathrm{NcoI-fragment} \mathrm{of} \mathrm{ceramide-}$ UDP-galactosyltransferase cDNA cloned in pGEM3Z; GAPDH, 550 bp HindIII and XbaI fragment of human liver glyceraldehyde-3-phosphate dehydrogenase cDNA (Arcari et al., 1984), fragments were purified using the Quiaex gel extraction kit (Quiagen, Chatsworth, CA); MAG, a myelin-associated glycoprotein cDNA fragment was obtained by applying RT-PCR, mouse MAG-specific sense primer (mmag5') binding to position 1351. 5'-AGAGCCACTGCCTTCAA-CCTGT-3'; mouse MAGspecific antisense primer (mmag $\left.3^{\prime}\right)$ binding to position 1910, 5'TCCTGGGGCTCTCAGTGACA-AT-3:

PCR primers were synthesized on an Applied Biosystems DNA Synthesizer, model $380 \mathrm{~A}$, and purified with SEP-PAK columns. For reverse transcription, 4 pg total rat brain poly A+ RNA was transcribed in $1 \times$ first strand buffer (Life Technologies, Inc., Gaithersburg, MD), $5 \mu \mathrm{M}$ p(dN)6 (Boehringer, Mannheim, Germany), 1 mM DTT, 20 U RNasin, $1 \mathrm{~mm}$ dNTPs, and $100 \mathrm{U}$ reverse transcriptase Superscript (Life Technologies, Inc., Gaithersburg, MD) in a total volume of $10 \mu \mathrm{l}$ for $2 \mathrm{hr}$

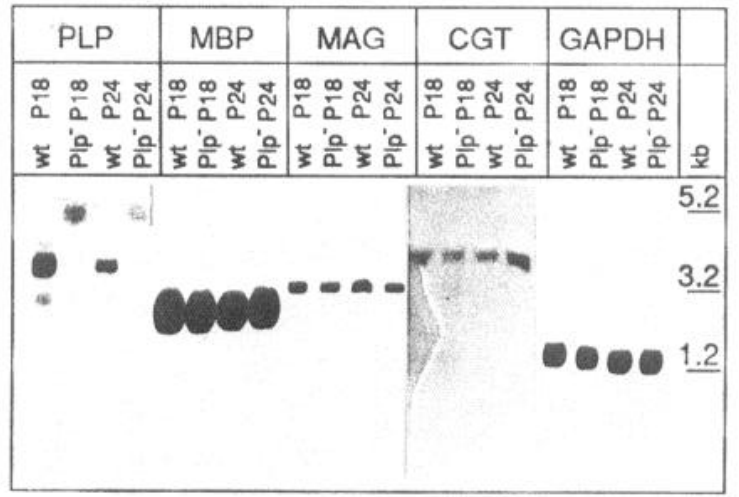

Figure 3. Northern blot analysis of PLP, MBP, MAG, CGT, and GAPDH mRNA in total brain RNA from 18- and 24-d-old wild type $(w t)$ and PLP-minus $\left(p l p^{-}\right)$mice. The RNA was separated in $1.5 \%$ formaldehyde-containing agarose gels and transferred to a nitrocellulose membrane, which was hybridized as indicated with probes for PLP, MBP, MAG, CGT, and GAPDH. 

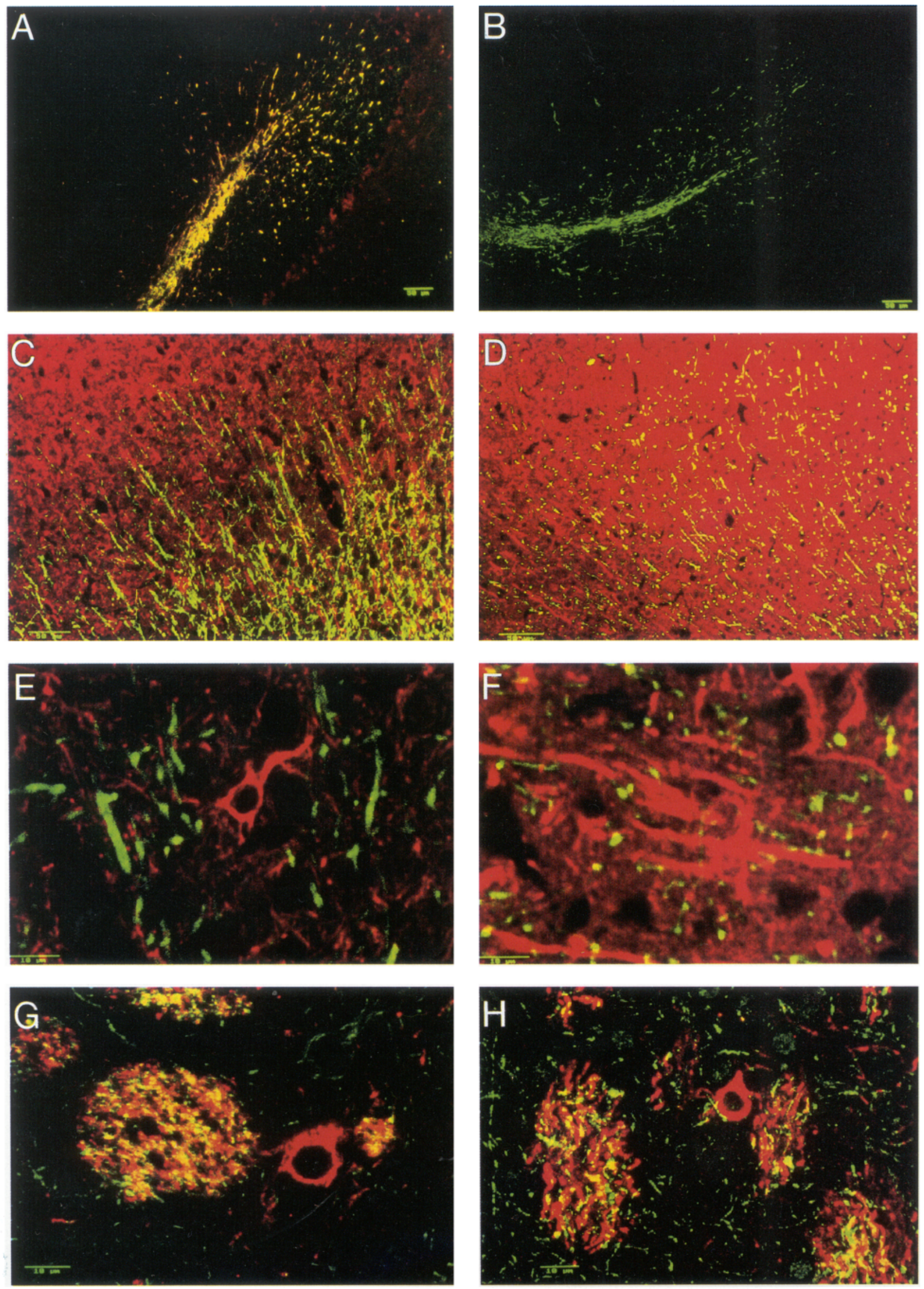


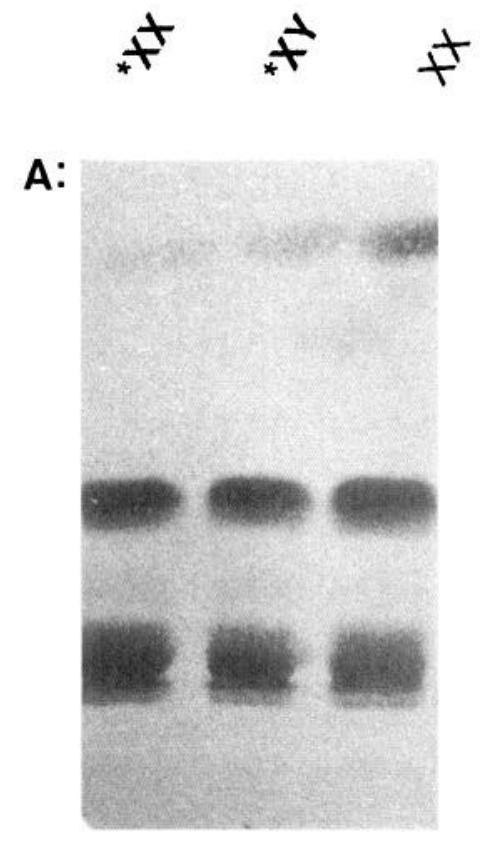

\section{Phospholipids}

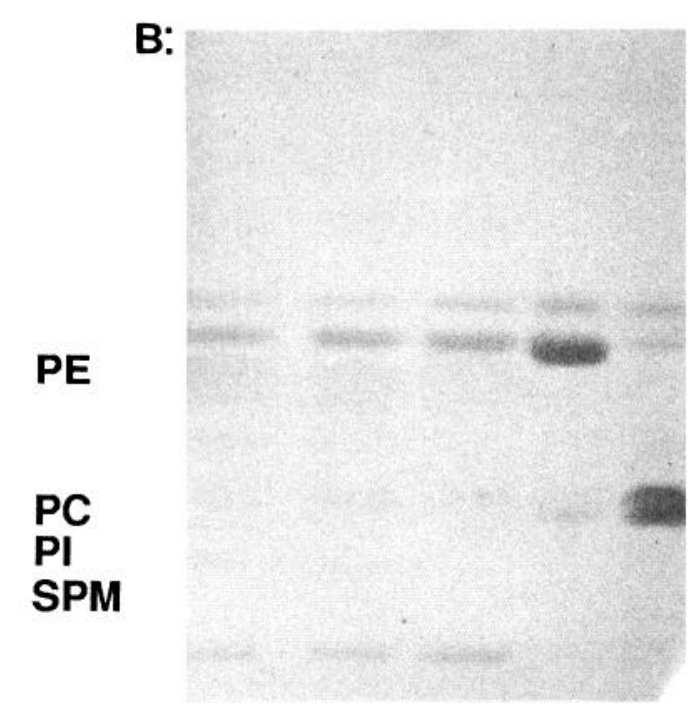

\section{Glycolipids}

Figure 5. Lipid analysis of chloroform-methanol extract of myelin of wild-type $(X X)$ and PLP-minus hemizygous $(* X Y)$ or heterozygous $(* X X)$ mutant mice. CNS myelin lipid extracts were separated by HPTLC in the solvent system, chloroform:methanol:water $60: 25: 4$. The locations of phosphatidylethanolamine $(P E)$, phosphatidylcholine $(P C)$, phosphatidylinositol $(P I)$, and sphingomyelin $(S P M)$ are indicated. A, Phospholipid stain, Zinzadze reagent (Dittmer and Lester, 1964). $B$, Glycolipid stain, $\alpha$-naphthol- $\mathrm{H}_{2} \mathrm{SO}_{4}$ reagent. at $37^{\circ} \mathrm{C}$. For the PCR reaction aliquots of $10 \mathrm{pmol}$ of each MAG primer (mmag $3^{\prime}$ and mmag $5^{\prime}$ ), $1 \mathrm{~mm} \mathrm{MgCl}_{2}, 10 \mathrm{~mm}$ dNTPs, $1 \times$ Taq polymerase buffer (Life Technologies, Inc.), and 2.5 U Taq-Polymerase (Life Technologies) were added to a total volume of $100 \mu \mathrm{l}$. PCR cycling was at $95^{\circ} \mathrm{C}$ for $1 \mathrm{~min}, 62^{\circ} \mathrm{C}$ for $1 \mathrm{~min}$, and $72^{\circ} \mathrm{C}$ for $1 \mathrm{~min}$ for a total of 40 cycles. The resulting $550 \mathrm{bp}$ amplification product was eluted from a $1.5 \%$ agarose gel.

Protein analysis. Myelin protein extracts of total brain $(50 \mu \mathrm{g} / \mathrm{lane})$ of wild-type, dm20neo and wtneo PLP-minus mice were separated on $15 \%$ SDS-PAGE. Gels were stained with Coomassie blue. For Western blot analysis, proteins were transferred to nitrocellulose by semidry blotting and immunostaining using 1:400 dilutions of anti-PLP peptide antibodies (Gly ${ }^{119}-$ Gly $^{127}$; Trp ${ }^{144}-\mathrm{Tyr}^{156}$, and $\mathrm{Thr}^{261}-\mathrm{Phe}^{276}$ ) and anti-myelin polyclonal rabbit serum. Alkaline phosphatase-coupled anti-rabbit antibody and bromoindolyl phosphate were used as substrate (Towbin et al., 1979).

Lipid analysis. Chloroform methanol $(2: 1 \mathrm{v} / \mathrm{v})$ extracts of total brain or of density gradient-purified myelin were separated by thin layer chromatography on HPTLC precoated plates, silica gel (Merck, Darmstadt; solvent system, chloroform:methanol:water 60:25:4). Phospholipids were stained with Zinzadze reagent (Dittmer and Lester, 1964) and glycosphingolipids visualized with $\alpha$-naphthol- $\mathrm{H}_{2} \mathrm{SO}_{4}$ in methanol-water $(1: 1$, $\mathrm{v} / \mathrm{v})$.

Rota-rod and open field test. A rod with a diameter of $3 \mathrm{~cm}$ was placed $20 \mathrm{~cm}$ above the ground. The rotation speed could be varied from 0.08 to $80 \mathrm{rpm}$. The animals were placed on the rod and the rotation speed was doubled every $60 \mathrm{sec}$. The time interval during which the mice stayed on the rotating rod was measured. Every mouse was tested in three successive trials. Mice groups $(n=5-6)$ consisted of the following genotypes and ages: wild-type males, 5 months; dm20neo males, 5 months; heterozygous females, 5 months; wild-type males, 3 months; dm20neo males, 3 months. The open-field test was performed according to Broadhust (1957), and was analyzed statistically.

Immunofluorescence labeling. Paraffin-embedded horizontal sections of cerebellum and longitudinal sections of cerebellum and brain of 4-week-old PLP-minus mice and wild-type controls were deparaffinized by submersion in xylene $2 \times 5 \mathrm{~min}$. Sections were rehydrated with Tris-buffered saline (TBS) and then blocked with TBS $/ 2.5 \%$ FCS for $15 \mathrm{~min}$. Incubations with primary antibody were performed over night at $4^{\circ} \mathrm{C}$. The following antibodies were used: monoclonal mouse antiMBP (Boehringer, Mannheim, Germany) (1:2000) and anti-neurofilament NF (Affiniti Research Products) (1:1000), and polyclonal rabbit anti-PLP (1:50), and affinity-purified anti MAG (1:500). Sections were washed three times in TBS, then incubated with the fluorescence-labeled second antibodies FITC-coupled anti-mouse IgG (1:130) (Sigma Chemical Co., St. Louis, MO) and Cy-3 coupled anti-rabbit IgG (1:800) (Dianova) followed by washing three times in TBS and then mounted in $2.5 \% \mathrm{Dabco} / \mathrm{TBS} / \mathrm{glycerol}$ for confocal immunofluorescence microscopy.

Optical sections of double-stained brain slices were analyzed with a Bio-Rad MRC-1000 confocal laser scanning system attached to a Nikon DIAPHOT 300 inverted microscope and using an argon-krypton laser as excitation light source. Confocal images of the $x, y$ plane of tissue sections were collected from two channels (488 or $568 \mathrm{~nm}$ wavelength). To examine the distribution of different antigens within the same specimen, data from both channels were overlaid to produce a single image. In the merged images, areas where the green and red fluorescent dyes colocalize appeared yellow. Slices of tissue incubated with secondary antibodies alone were also scanned and showed no fluorescent signal.

$\leftarrow$

Figure 4. Confocal optical sections of wild-type $(A, C, E$, and $G)$ and PLP-minus $(B, D, F$, and $H)$ mouse brains. $A$ and $B$, Cerebellum longitudinal sections double labeled for MBP (green) and PLP (red). A, The two antigens colocalize in the wild-type (in yellow). B, No PLP immunostaining is detectable in the PLP-minus mutant. $C-F$, Cortex longitudinal sections immunostained for MBP (green) and MAG (red). Merged images show a scattered MBP distribution in the PLP-minus animals $(D$ and $F$ ) compared to controls $(C$ and $E)$. $F$, Mutant oligodendrocytes express MAG more widely than $(E)$ wild-type oligodendrocytes. $G$ and $H$, Superimposed images of NF (green) and MAG (red) immunostaining showing an oligodendrocyte myelinating nerve bundles. No differences are observed in the distribution of the two staining patterns between control $(G)$ and mutants $(H)$ mice. Scale bars: $A-D, 50 \mu \mathrm{m} ; E-H, 10 \mu \mathrm{m}$. 
A

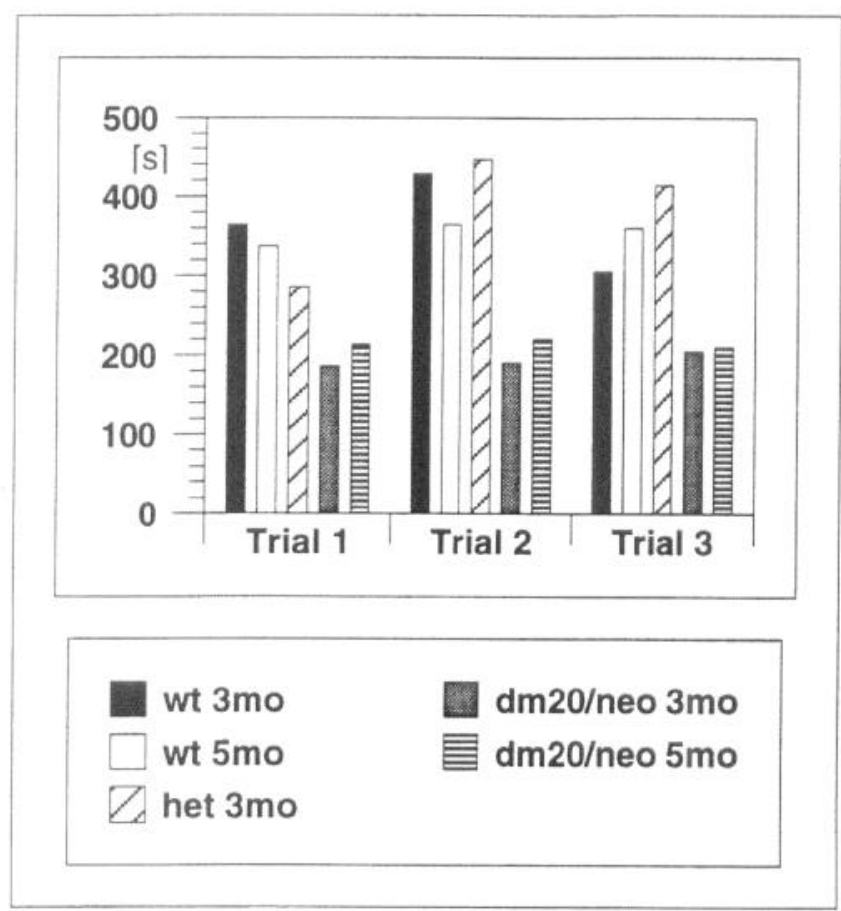

B

Figure 6. A, Performance in the Rota-Rod test. The bars represent the total time in seconds for which the mice stayed on the rod in three successive trials. Each value is the average of five to six littermates. Genotypes and ages: wild-type males, 3 months ( $w t$ $3 \mathrm{mo}$ ); wild-type males, 5 months ( $w t$ $5 \mathrm{mo}$ ); heterozygous females, 5 months (het $3 \mathrm{mo}$ ); mutant males, 3 months (dm20neo $3 \mathrm{mo})$; mutant males, 5 months (dm20neo 5mo). B, Locomotor activity of normal and transgenic mice measured in the open-field test. Open circles: wt-control mice; filled circles: transgenic dm20neo mice. The horizontal activity of the mice was counted by movements through a light barrier grid. After $30 \mathrm{~min}$, an unknown object was placed into the box provocating exploration behavior.

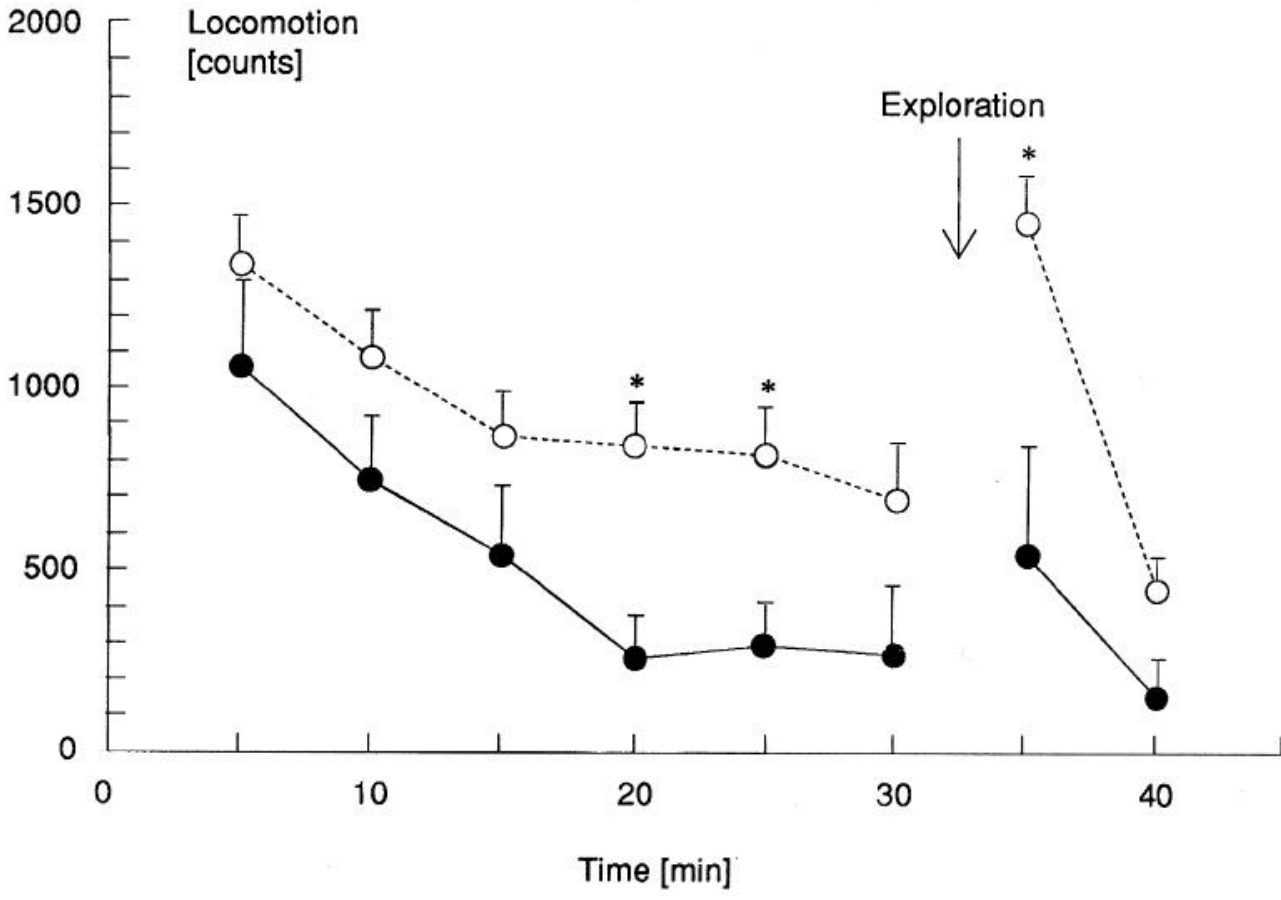

Electron microscopy. Mice $29 \mathrm{~d}$ old were anesthetized with Nembutal and perfused with $6 \%$ glutaraldehyde via the left cardiac ventricle. Cervical segments of the spinal cord were obtained and the optic nerve was removed between the eyeball and the orbital fissure, postfixed in $1 \%$ phosphate-buffered $\mathrm{OsO}_{4}$ in $0.1 \mathrm{M}$ sucrose, and embedded in Epon 812. Ultrathin cross sections of optic nerve and spinal cord were contrasted with uranyl acetate and lead citrate and examined as described before (Büssow, 1978).

\section{Results}

The targeting of the PLP gene leads to a complete PLP and DM20 loss in transgenic mice

Previous Northern blot analyses revealed that abnormal PLPtranscripts of $5.2 \mathrm{~kb}$, present in PLP-minus mice, hybridize exclusively with probes specific for all exons and intron III of the 

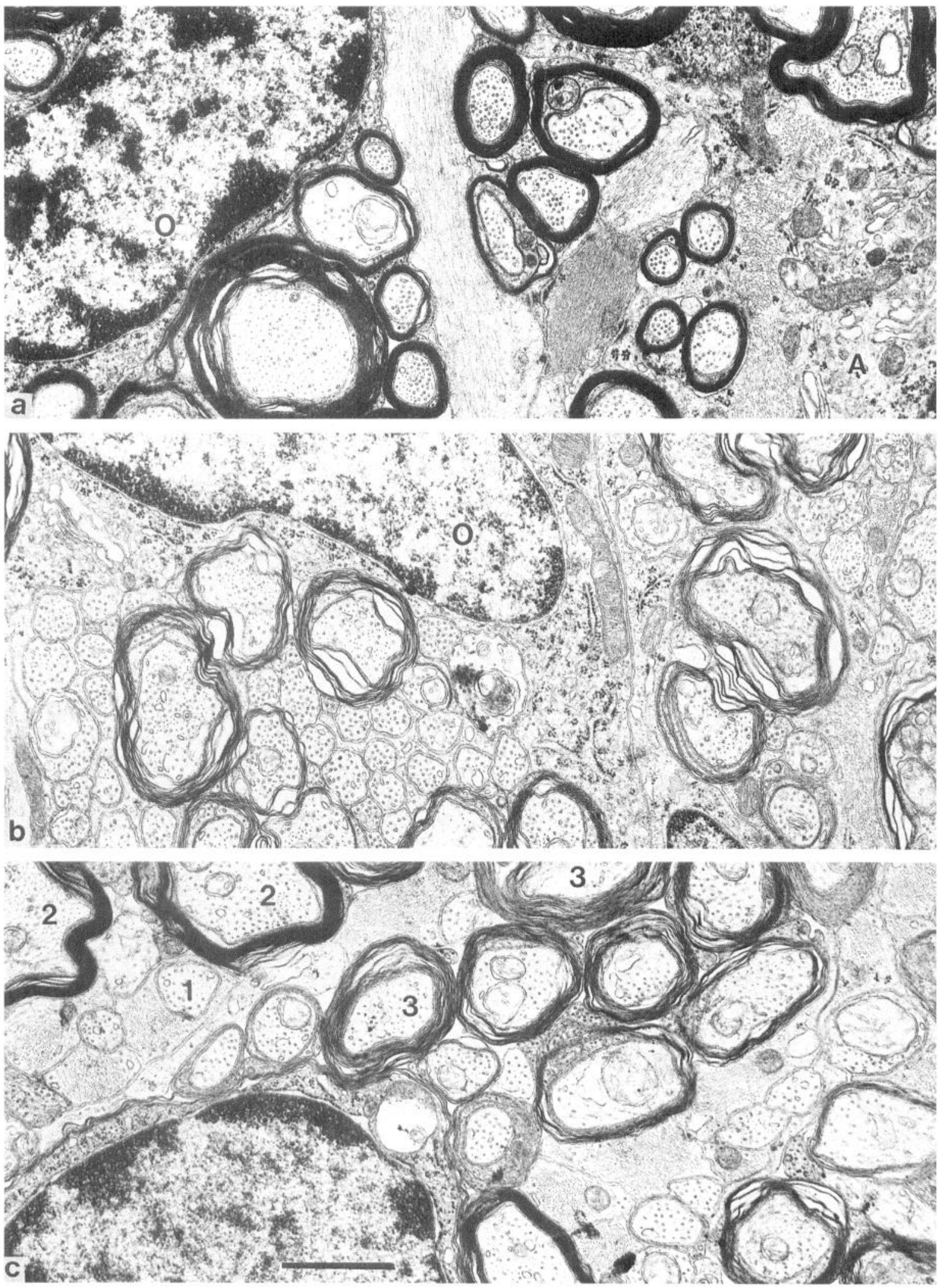

Figure 7. Electron micrographs of cross sections of optic nerves of 29-d-old mice. $a$, Wild-type plp ${ }^{+/+}$-mouse: all axons possess a typically compacted CNS myelin sheath. Oligodendrocytes $(o)$ are characterized by a small perinuclear cytoplasm and compact chromatin in their nuclei. $A$ : Astrocyte. $b$, Hemizygous $p l p^{-}$-mouse: in contrast to the wild type, most of the small axons are devoid of a myelin sheath and are encompassed by astrocytic processes. Only larger axons are surrounded by a noncompacted myelin sheath, which is characterized by increased looseness of their lamellae. The perikarya of the oligodendrocytes $(o)$ are characterized by a wide perinuclear cytoplasm with a prominent RER and Golgi apparatus. $c$, Heterozygous $p l^{+1-}$-mouse: some small axons are devoid of their myelin sheath $(1)$. Most axons are ensheathed either with a typically compacted CNS myelin sheath (2) or with a noncompacted myelin sheath (3) characteristic for PLP-minus mice. Scale bar, $1.2 \mu \mathrm{m}$. 

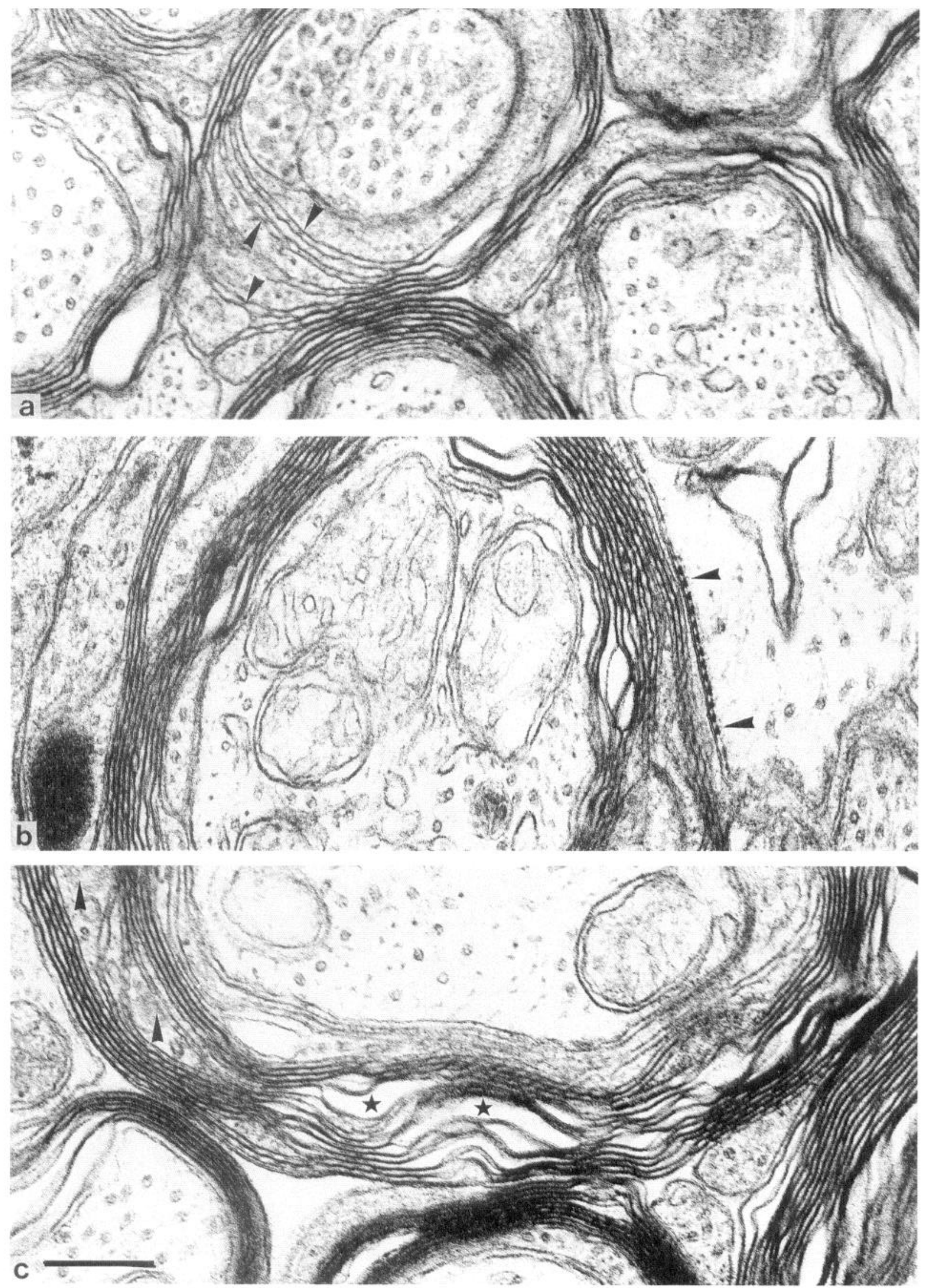

Figure 8. Typical PLP-minus CNS myelin sheaths in the optic nerves of 29-d-old hemizygous $p l p^{-}-(a$ and $b)$ and heterozygous plp $p^{+1-}-$ mice. $a$, The paranodal lamellae of the oligodendrocyte form only incomplete major dense lines (MDLs). In place of a continuous intraperiod dense line 
PLP gene and the neo-cassette. These results led us to propose an antisense-RNA-mediated mechanism of gene silencing (Boison and Stoffel, 1994). Figure 1 shows the nature of the aberrantly spliced $5.2 \mathrm{~kb}$ transcript. Myelin of brains of wild-type and mutant PLP-minus mice was isolated by sucrose-gradient centrifugation (Norton and Poduslo, 1973). The myelin proteins were size fractionated by SDS-PAGE and transferred to nitrocellulose by the semidry blot technique. The blot was incubated with affinity-purified antibodies raised against synthetic peptides of amino acid sequences of the hydrophilic loops of PLP (Gly ${ }^{19}-$ Gly $^{127}$; Trp ${ }^{144}-$ Tyr $^{156}$; Thr ${ }^{261}-\mathrm{Phe}^{276}$ ) under standard conditions. An alkaline phosphatase-labeled second antibody was used as detection system. The hands of PI.P and DM20 from wild-type brain myelin were intensively stained, whereas PLP and DM20 proteins were completely absent in protein extracts of mutant mice (Boison and Stoffel, 1994) and in Western blot analysis (Fig. 2).

Expression of the oligodendrocyte-specific genes (MBP, MAG, CGT) is not impaired by the PLP deficiency

RNA of brains of homozygous PLP-minus mice were also probed for the expression of other oligodendrocyte specific genes, which are temporally regulated in parallel to the PLP gene. An MBP-specific 620 bp cDNA probe (Schaich et al., 1986), a 500 bp MAG-specific PCR fragment, and a $700 \mathrm{bp}$ fragment of the CGT-specific cDNA (Schulte and Stoffel, 1993) were used as probes. Signals were correlated with the hybridization signal of glyceraldehyde-3-phosphate dehydrogenase (GAP-DH) as an internal control (Fig. 3). We could not detect any alterations of the expression pattern of the MBP, MAG, and CGT genes in 18- to 24-d-old mutants as compared with wildtype controls of the same age. They are expressed in oligodendrocytes of brains of homozygous and heterozygous mutant mice comparable to those of the wild type.

\section{Immunofluorescence analysis of brain sections by confocal microscopy}

In order to investigate the distribution of myelin specific gene products in situ, we performed a double immunofluorescence analysis in brain sections of 4-week-old PLP-minus and wildtype control mice (Fig. 4). As expected, we were not able to detect any PLP-specific signals in the mutant animals (Fig. $4 B$ ). The distribution of MBP and MAG in the targeted mice differs from the distribution in the controls (Fig. 4A). In PLP-minus mice MBP appears in patches (Fig. $4 D, F$ ), but in controls homogeneously along the myelinated fibers (Fig. $4 C, E$ ). In the mutants, MAG is distributed more widely than in the control, which suggests that it is responsible for the ensheathment of myelindeficient axons. There is no colocalization of MBP and MAG (Fig. $4 C-F$ ). In the controls, MAG is only visible in the perikarya of oligodendrocytes and in processes leading to myelinated MBP-containing fibers (Fig. 4F). This suggests that MAG is assembling only in areas containing no or uncompacted myelin. Apparently no differences exist between oligodendrocytes in wild-type (Fig. $4 G$ ) and plp $-/$ - mutant (Fig. $4 H$ ) in neigh- boring nerve fibers. This is consistent with the morphology in electron microscopy (see Fig. 9).

\section{Lipid analysis of CNS myelin of wt, hetero-, and homozygous PLP-minus mice}

Total brain lipids of wild-type, hetero-, and homozygous mutant mice were extracted with chloroform-methanol (2:1) and separated by HP-TLC. Phospho- and glycolipids were detected with specific reagents (Dittmer and Lester, 1964). The pattern of both lipid classes of brain of the three phenotypes were indiscriminantly similar. The synthesis of the oligodendrocyte-specific cerebrosides (galactosylceramides) and sulfatides is unimpaired by the loss of the expression of the main integral membrane myelin protein of CNS (Fig. 5).

\section{Behavioral analysis}

We assayed the neuromotor coordination in the Rota Rod apparatus. Three- and five-month-old wild-type, hetero-, and homozygous PLP-minus mice were compared. The time interval during which the mice with the three genotypes were able to stay on the rotating rod under identical conditions are summarized in Figure 6A. By averaging the data of three trials and by comparing the total time during which the mice were able to stay on the rotating rod, we estimated a $\sim 50 \%$ reduction of the neuromotor coordination of the transgenic mouse compared to the wild type. This factor corresponds to the reduced velocity of conduction measured in the optic nerve. In the open-field test, we analyzed the spontaneous activities registered by horizontal and vertical movements of control and mutant mice. The plpmice show a remarkably reduced spontaneous activity. Their response to a movement in the exploratory field (deposition of the tag of the cage) is distinctly reduced (Fig. 6B).

\section{Hemi- and homozygous PLP-minus myelin ultrastructure}

In order to investigate the ultrastructure of CNS myelin we investigated cross sections of optic nerve and spinal cord (identical data not shown) as representative parts of the CNS by electron microscopy. In the optic nerve of wild-type mice all axons are myelinated with regularly compacted CNS myelin sheaths, and oligodendrocytes show a typical dense small perikaryon (Fig. $7 a$ ). By contrast, in sections of PLP-minus hemizygous male as well as in homozygous female mice most small diameter axons lack their myelin sheath and are surrounded only by astrocyte processes. Axons with large diameters are ensheathed by a loosely structured multilayer membrane system. Perikarya of oligodendrocytes are enlarged and a high metabolic activity is reflected by an extensively developed rough endoplasmic reticulum and Golgi apparatus (Fig. 7b).

At high magnification, the PLP-minus myelin sheath (Fig. 7) exhibits only one electron dense line that can be assigned to the major dense line (MDL), whereas the intermediate dense line (IDL) is missing. The spirally wrapping loops are separated by large and uneven extracellular spaces and appear as loose coils in cross sections. Occasionally, focal contacts are formed between the outer membrane surfaces with a staggered regular

$\leftarrow$

(IDL) the adjacent lamellae form only focal contacts (arrowheads). $b$, These focal contacts are also observed occasionally in the internodal section of the myelin sheath and show an apparently staggered configuration. The outermost lamella of this oligodendrocyte shows morphologically normal axoglial contacts (arrowheads). $c$, The optic nerve of the heterozygous mouse shows a cellular mosaicism that is documented by the simultaneous occurrence of two apparently normal myelin sheaths and two typical PI.P-minus myelin sheaths, showing cytoplasmic inclusions (arrowheads) and a widened extracellular space between the lamellae $\left(^{*}\right)$. Scale bar, $0.28 \mu \mathrm{m}$. 
spacing in a given sector of the PLP-minus myelin sheath (Fig. 8).

The paranode of the PLP-minus sheath shows typical cytoplasmic inclusions in the lateral loops of the oligodendrocyte lamellae. However, the axoglial contacts between the lateral loops and the axolemma appear normal in cross sections (Fig. $8 a$ ) as well as in longitudinal sections (Fig. 9).

\section{Heterozygous $\mathrm{plp}^{+1-}$ myelin ultrastructure}

Cross sections of optic nerve (and of spinal cord; data not shown) of 29-d-old heterozygous $\mathrm{plp}^{+1-}$ mice (Figs. $7 c, 8 c, 10 b$ ) show a mosaicism with groups of nerve fibers with normally compacted CNS myclin sheaths adjacent to axons wrapped by PLP-minus myelin sheaths. Additionally, longitudinal sections of spinal cord (Fig. 9a) prove that subsequent internodes of one myelinated axon are addressed both by processes of oligodendrocytes expressing the $\mathrm{X}$-chromosomal $p l p^{+}$-allele and by oligodendrocytes expressing the $p l p^{-}$-allele. On a cellular level, this reflects the random $\mathrm{X}$-inactivation during Barr-body formation. No deficits in peripheral myelination were observed, which is consistent with the CNS specificity of PLP (Fig. 10a).

\section{Discussion}

The myelin sheath of CNS axons is a specialized multilamellar membrane system of unique organization. During myelination, specific lipid and protein components are assembled into the highly ordered plasma membrane of the tongue-like processes of oligodendrocytes. They address up to 100 axons and ensheathe them in a wrapping process in which the cytoplasm is "squeezed" out, and the surfaces of the inner leaflets become closely apposed forming the major dense line. MBP has an important functional impact on this apposition process in CNS myelination where it accounts for 35 to $40 \%$ of myelin proteins (Roach et al., 1983; Readhead et al., 1987). MBP-deficient shiverer mice exhibit a loss of the major dense line which is attributed to MBP interacting with the apposing cytosolic surfaces (Rosenbluth, 1980).

A clue for adhesive functions of proteolipid protein (PLP) comes from the topology of this main myelin protein constituent, which accounts for more than $50 \%$ of the total myelin protein. Biochemical studies (Weimbs and Stoffel, 1992) suggest a four transmembrane helices topology with highly charged extracytosolic loops suited for homo- or heterophilic interactions. This leads to the close apposition of the outer membrane leaflets of adjacent loops and formation of the intermediate dense line.

We studied the impact of the structure and function of PLP and its isoprotein DM20 in vivo by gene targeting. The wildtype PLP gene of the mouse at the plp locus on chromosome $\mathrm{Xq} 23$ we replaced with $p l p$ constructs in which the neomycin resistance gene as the selection marker was placed in reverse orientation into intron III. In hemi- and homozygous mutant mice, the PLP/DM20 mRNAs at 1.6, 2.4, and $3.2 \mathrm{~kb}$ were completely missing in total brain RNA. Consequently, none of the PLP isoproteins was detectable in SDS-PAGE of CNS myelin extracts, nor in situ in immunolabeled brain sections.

On the RNA level no functional compensation for the lack of
PLP by other myelin proteins was observed, as confirmed by Northern blot hybridization analysis with probes for other myelin proteins, for example, myelin basic protein (MBP), myelin associated glycoprotein (MAG), and the oligodendrocyte-specific UDP-galactose ceramide galactosyl transferase (CGT). This indicates that the PLP-deficiency did not influence the expression of these genes. The results reported here are in contrast to the pleiotropic effect of naturally occurring point mutations leading to premature death of oligodendrocytes and a lack of all oligodendrocyte-specific gene products. Immunofluorescence analysis, shown in Figure 4, suggests that in the mutants MAG is more widely distributed along nerve fibers, particularly in arcas that lack MBP-positive myelin. Thus, MAG, with its adhesive properties, may compensate for the lack of PLP, permitting the establishment of axoglial contacts and the first round of axonal isolation.

The inactivation of the PLP gene expression described here allows insight into the role of PLP for the structural organization of the CNS myelin membrane. The disrupted myelin ultrastructure leads to a loss of the insulating properties, which can be quantified by measuring the conductance velocity of the optic nerve, which is reduced by 50\% in the PLP-minus mutants (Gutierrez et al., submitted). These altered conductance properties are also reflected in the behavioral deficits of the mutant transgenic mice.

The morphological data presented here and in analyses of the ultrastructure of scattered myelinated fibers seen in the jimpy mouse and md rat (Duncan et al. 1987, 1989) provide evidence that PLP is responsible for the tight adhesion of the outer membrane surfaces leading to the formation of the intermediate dense line (IDL). We propose that this adhesion is mediated directly by the hydrophilic extracellular domains of PLP. Whether other than adhesion functions of PLP are operative as derived from evolutionary considerations (Kitagawa et al., 1933; Yan et al., 1993) remains to be proven. Despite the disruption of the highly ordered and compacted myelin membrane in the PLP-minus mice with its functional consequences, surprisingly, these mutant mice are fertile and live as long as wild-type controls without any very obvious behavioral symptoms. Deficits in their behavior can be established only in specialized tests. The major difference to natural-occurring mutants, carrying point mutations in the PLP-gene, which show a much more severe phenotype, lies in the absence of early oligodendrocyte death in PLP-minus mice. In the morphological part of these studies, we were unable to detect any signs of oligodendrocyte cell death. In the mutant mouse, the PLP-minus oligodendrocyte processes form an axoglial contact, which apparently is sufficient to provide the most basic insulator functions, thus preventing more dramatic deficits. MAG seems to be responsible for the preservation of the axoglial contacts, as has been demonstrated by the creation of a MAG knock-out mouse ( $\mathrm{Li}$ et al., 1994).

Our results prove that life and reproduction arc compatible with a severely altered structure of the CNS myelin sheath, which completely lacks the main integral membrane protein components PLP and DM20. This protein deficiency neither interferes with oligodendrocyte differentiation nor causes prema-

\footnotetext{
Figure 9. Longitudinal section of nodes of Ranvier in the spinal cord of a heterozygous 29-d-old PLP-minus mouse. $a$, The paranode on the left shows a normally compacted myelin sheath, whereas the paranode on the right shows the loosened structure characteristic for the homozygous PLP-minus CNS myelin sheath. $b$, The lateral loops of a PLP-minus myelin sheath form apparcntly normal axoglial junctions. Scale bars: $a$, 0.9 $\mu \mathrm{m} ; b, 0.28 \mu \mathrm{m}$.
} 


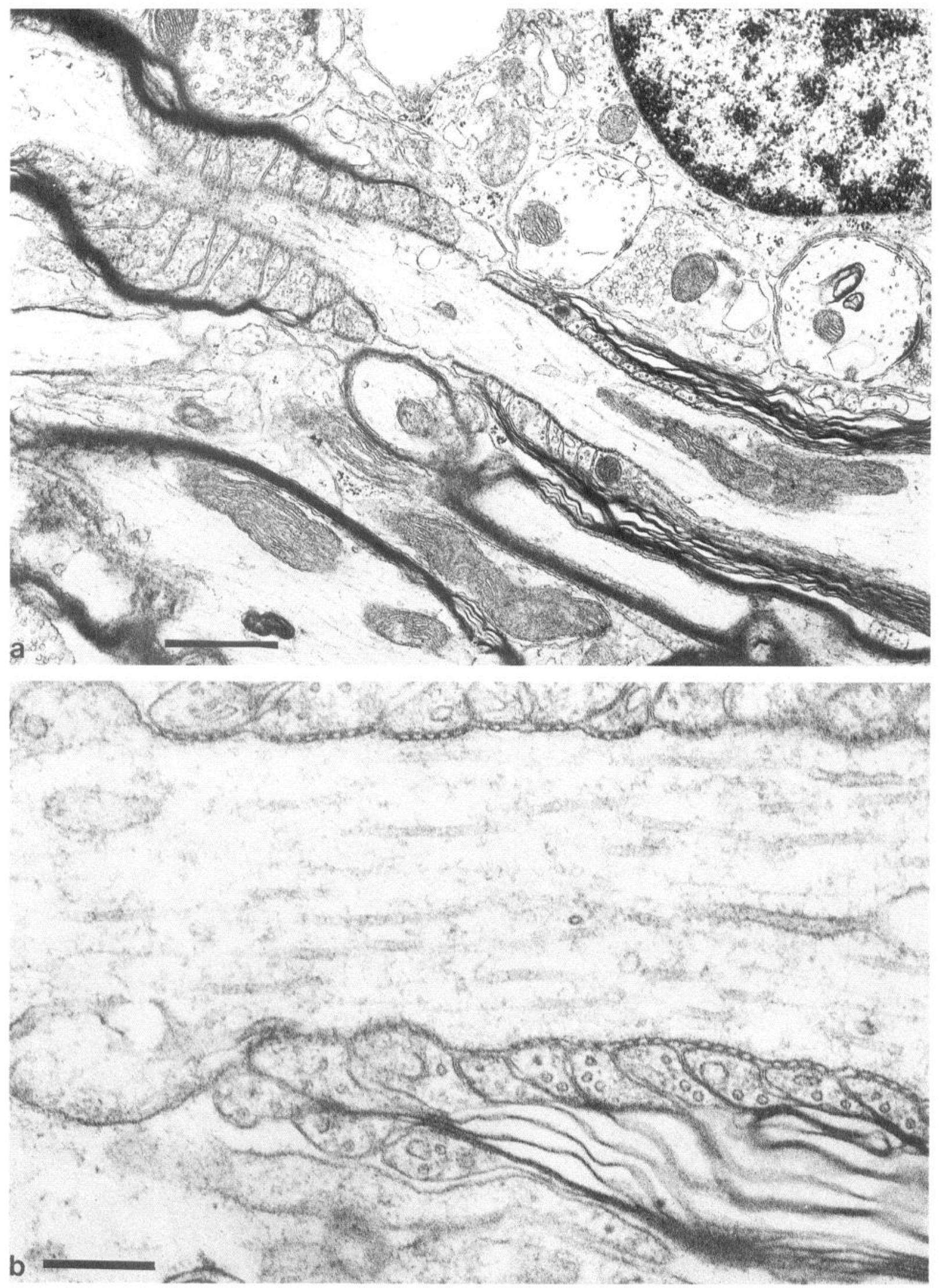



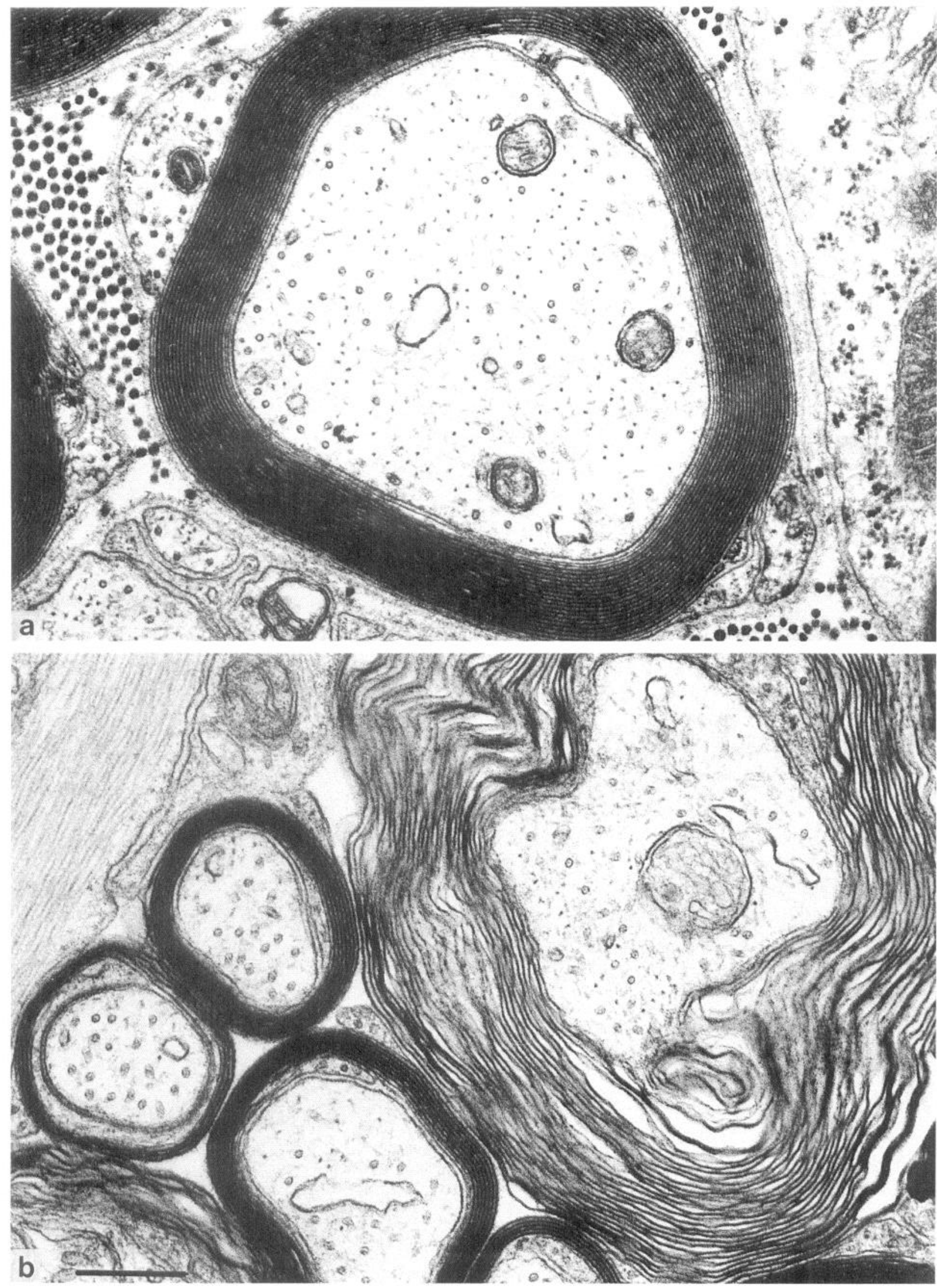

Figure 10. Electron micrographs of PNS $(a)$ and CNS $(b)$ axons of one 29-d-old heterozygous mouse. $a$, All myelinated axons in the fascicles of peripheral nerves show morphologically normal PNS-myelin sheaths. $b$. Three small CNS axons in the optic nerve with a normally compacted CNS myelin sheath are adjacent to a large axon, myelinated by loose lamellae lacking the intraperiod dense line. Consequently, the PLP-minus CNS myelin sheath has the form of loose coils in which only the major dense line is present. Scale bar, $0.4 \mu \mathrm{m}$. 
ture oligodendrocyte death. In contrast, in dysmyelinated phenotypes caused by natural PLP point mutations or transgenic overexpression of the PLP gene (Kagawa et al., 1994; Readhead et al., 1994) glial cell degeneration causes severe neurological symptoms and premature death of the afflicted individual. We propose that in these cases either misfolded PLP or PLP in excess of MBP prohibits the proper integration into the myelin membrane by forming hydrophobic aggregates resistant to proteolytic degradation. This "hydrophobic junk" may lead to perturbation of membrane trafficking or other intracellular disturbances that lead to cell death. On a first look, the rumpshaker mouse (Schneider et al., 1992) seems to be similar to the PLPminus mouse, due to the lack of oligodendrocyte death. The major difference is that in the rumpshaker mutant, PLP is present. We propose that the rumpshaker mutation does not exert the toxic effect observed in the other natural mutant PLP variants.

Thus, the PLP/DM20 knock-out mouse might become an important model for future molecular myelin pathology. Further insight into the interaction of defect and missing myelin constituents will come from breeding respective genotypes.

\section{References}

Arcari P, Martinelli R, Salvatore F (1984) The complete sequence of a full length cDNA for human liver glyceraldehyde-3-phosphate dehydrogenase: evidence for multiple DNA species. Nucleic Acids Res 12:9179-9189.

Arquini M, Roder J, Loo-Sar C, Down J, Wilkinson D, Bayley H, Braun $\mathrm{P}$, Dunn R (1987) Molecular cloning and primary structure of myelin-associated glycoprotein. Proc Natl Acad Sci USA 84:600-604.

Boison D, Stoffel W (1989) Myelin-deficient rat: a point mutation in exon III (A $\rightarrow$ C, Thr75 $\rightarrow$ Pro) of the myelin proteolipid protein causes dysmyelination and oligodendrocyte death. EMBO J 8:32953302.

Boison D, Stoffcl W (1994) Disruption of the compacted myelin sheath of axons of the central nervous system in proteolipid protein deficient mice. Proc Natl Acad Sci USA 91:11709-11713

Broadhust PL (1957) Determinants of emotionality in the rat. 1. Situational factors. Br J Psychol 48:2-12.

Büssow H (1978) Schwann cell myelin ensheathing CNS axons in the nerve fibre layer of the cat retina. J Neurocytol 7:207-214.

Chomczynski P, Sacchi N (1987) Single-step method of RNA isolation by acid guanidinium thiocyanate-phenol-chloroform extraction. Anal Biochem 162:156-159.

Diehl H-J, Schaich M, Budzinski R-M, Stoffel W (1986) Individual exons encode the integral membrane domains of human myelin proteolipid protein. Proc Natl Acad Sci USA 83:9807-9811.

Dittmer J, Lester R (1964) A simple, specific spray for the detection of phospholipids on thin-layer chromatograms. J Lipid Res 5:126127.

Duncan ID, Hammang JP, Trapp BT (1987) Abnormal compact myelin in the myelin deficient rat: absence of proteolipid protein correlates with a defect in the intraperiod line. Proc Natl Acad Sci USA 84: 6287-6291.

Duncan ID, Hammang JP, Goda S, Quarles RH (1989) Myelination in the jimpy mouse in the absence of proteolipid protein. Glia $2: 148$ 154.

Eylar EH (1970) Amino acid sequence of the basic protein of the myelin membrane. Proc Natl Acad Sci USA 67:1425-1431.
Kagawa T, Ikenaka K, Inoue Y, Kuriyama S, Tsujii T, Nakao J, Nakajima K, Aruga J, Okano H, Mikoshiba K (1994) Glial cell degeneration and hypomyelination caused by overexpression of myelin proteolipid protein gene. Neuron 13:427-442.

Kamholz J, de Ferra F, Puckett C, Lazzarini R (1986) Identification of three forms of human myelin basic protein by cDNA cloning. Proc Natl Acad Sci USA 83:4962-4966.

Kitagawa K, Sinoway MP, Yang C, Gould RM, Colman DR (1993) A proteolipid protein gene family: expression in sharks and rays and possible evolution from an ancestral gene encoding a pore-forming polypeptide. Neuron 11:433-448.

Li C, Tropak MB, Gerlai R, Clapoff S, Abramow-Newerly W, Trapp B, Peterson A, Roder J (1994) Myelination in the absence of myelinassociated glycoprotein. Nature 396:747-750.

Milner R, Lai C, Nave K, Lenoir D, Ogata J, Sutcliffe J (1985) Nucleotide sequences of two mRNAs for rat brain myelin proteolipid protein. Cell 42:931-939.

Nave K, Lai C, Bloom F, Milner R (1986) .Jimpy mutant mouse: a 74 base deletion in the mRNA for myelin proteolipid protein and evidence for a primary defect in RNA splicing. Proc Natl Acad Sci USA 83:9264-9268.

Norton W, Poduslo S (1973) Myelination in rat brain: method of myelin isolation. J Neurochem 21:749-757.

Readhead C, Popko B, Takahashi N, Shine H, Suavedra R, Sidman R, Hood L (1987) Expression of a myelin basic protein gene in transgenic shiverer mice: correction of the dysmyelinating phenotype. Cell 48:703-712.

Readhead C, Schneider A, Griffiths I, Nave K-A (1994) Premature arrest of myelin formation in transgenic mice with increased proteolipid protein gene dosage. Neuron 12:583-595

Roach A, Boylan K, Horvath S, Prusiner S, Hood L (1983) Characterization of cloned cDNA representing rat myelin basic protein: absence of expression in brain of shiverer mutant mice. Cell 34:799806

Rosenbluth J (1980) Central myelin in the mouse mutant shiverer. J Comp Neurol 194:639-648.

Schaich M, Budzinski R-M, Stoffel W (1986) Cloned proteolipid protein and myclin basic protein cDNA. Biol Chem Hoppe-Scyler 367: $825-834$.

Schneider A, Montague P, Griffiths I, Fanarraga M, Kennedy P, Brophy P, Nave K-A (1992) Uncoupling of hypomyelination and glial cell death by a mutation in the proteolipid protein gene. Nature 358:758761.

Schulte S, Stoffel W (1993) Ceramide UDP-galactosyltransferase from myelinating rat brain: purification, cloning and localization. Proc Natl Acad Sci USA 90:10265-10269.

Stoffel W, Hillen H (1983) The primary structure of bovine brain myelin lipophilin (proteolipid apoprotein). Hoppe-Seyler's Zeitschr Physiol Chemie 364:1455-1466.

Takahashi N, Roach A, Taplow D, Prusiner S, Hood L (1985) Cloning and characterization of the myelin basic protein gene from mouse: one gene can encode both $14 \mathrm{kd}$ and $18.5 \mathrm{kd}$ MBPs by alternate use of exons. Cell 42:139-148.

Towbin H, Staehelin T, Gordon J (1979) Electrophoretic transfer of protcins from polyacrylamide gels to nitroccllulose sheets: procedure and some applications. Proc Natl Acad Sci USA 76:4350-4354.

Weimbs T, Stoffel W (1992) Proteolipid protein (PLP) of CNS myelin: positions of free, disulfide bonded, and fatty acid thioester-linked cysteine residues. Implications for the membrane topology of PLP. Biochemistry 31:12289-12296.

Willard H, Riordan J (1985) Assignment of the gene for myelin proteolipid protein to the X chromosome: implications for X-linked myelin disorders. Science 230:940-942.

Yan Y, Lagenaur C, Narayanan V (1993) Molecular cloning of M6: identification of a PLP/DM20 gene family. Neuron 11:423-431. 